\title{
Experiences with Tutored Video Instruction for Introductory Programming Courses
}

\author{
Richard Anderson and Martin Dickey and Hal Perkins \\ Department of Computer Science and Engineering, University of Washington \\ Seattle, WA 98195-2350 \\ \{anderson, dickey, perkins\}@cs.washington.edu
}

\begin{abstract}
In this paper we describe our experiences of exporting our introductory programming courses to community colleges. We used Tutored Video Instruction (TVI) as the mode of instruction where recorded versions of our lectures were shown to groups of students with local instructors periodically stopping the lecture for questions and discussion.
\end{abstract}

We have offered a total of 16 sections of TVI courses, 11 were of our first quarter programming coures (CSE142), and 5 were of our second quarter programming course (CSE 143). The courses were offered at seven institutions. Approximately 180 students completed the courses.

We identify factors which contributed positively and negatively to the use of TVI for introductory programming courses. The two most important changes to our TVI program based on these experiences will the use of studio produced lectures and the abandonment of centralized course administration.

\section{Introduction}

There is tremendous interest in using archived lecture material to support offerings of university courses. The attraction comes from (perceived) reductions in cost, difficulties in recruiting qualified instructors, and greater flexibility for students because of time or location. The computing and communication revolution has enabled new methods of content distribution and reduced many of the costs associated with producing, storing, transmitting, and viewing archived lecture material. A question of fundamental importance is how can we take advantage of this technology to effectively educate our students. This includes possibly shifting away from the traditional large lecture mode of instruction at universities, as well as making university courses accessible to a broader range of student.

We have two years of experience of teaching our introductory programming courses at local community col- leges using a Tutored Video Instruction model. We have offered a total of 16 sections of two courses and have involved seven sites. This paper presents an overview of the project, and also draws some conclusions based on our experiences. The lectures and other course materials, along with information about participants in the project, are available from the course web site. ${ }^{1}$

\subsection{Tutored Video Instruction}

Tutored Video Instruction (TVI) [1] was pioneered by Jack Gibbons and his colleagues at Stanford in the late 1970's. The basic premise was that students learn much better from videotapes if in a group with a facilitator to engage students in discussion about the material. Gibbons makes a compelling case that TVI instruction was effective in various engineering domains. He gave experimental results which showed TVI was not only better than watching video tapes alone, but that TVI instruction compared favorably to in-class instruction.

The tutor for a TVI course need not be an instructor who is fully qualified to teach the course, but a "paraprofessional" who can lead discussion, and help students resolve questions about the material. In the theoretical TVI model, the students should be in a small group (but not too small), and the tutor should not perform a grading role for the course.

We were interested in reproducing Gibbon's success with TVI in the introductory programming domain. The development of video streaming technology allowed us to create and distribute lectures at low cost (so it was no longer Tutored Videotape Instruction).

\subsection{Origins of our experiments}

At University of Washington, we have a two quarter introductory computing sequence, CSE 142 and CSE 143. These courses currently use $\mathrm{C}$ and $\mathrm{C}++$, and are taught in a traditional large lecture format. Each quarter CSE 142 has two lecture sections of 250 students each, and

\footnotetext{
${ }^{1}$ www.cs.washington.edu/education/TVI
} 
CSE 143 has one lecture section of 250 students. Both courses have three hours of lecture per week. CSE 142 has one hour of quiz section, and CSE 143 has two hours of quiz section. The courses each have roughly five programming assignments per quarter, plus midterms and a final. The courses have a reputation as being difficult, and have a high drop rate. Admission to the CS/CSE major is competitive which adds to the pressure that some students experience.

The reason that we were interested in exporting our courses is that the State of Washington has a large community college system with many students transferring courses to 4-year institutions. We want to make it possible for community colleges to offer a course which students could transfer to UW. This is an issue both of course credit, as well as preparation for follow on work. Many community colleges have substantial difficulty in attracting and retraining qualified instructors. The appeal of the TVI model is that it allows community colleges to offer our materials, using instructors with less experience in computing, and still having interaction with students in small classes.

We were also motivated by the desire to gain experience with distance learning and technology used in education. Many academics have serious concerns about the push towards distance education, but there are certainly opportunities to use technology that will help students receive a better education (as opposed to just reducing costs). We also want to understand how well Tutored Video Instruction works, since it has the potential for broad use in our curriculum.

\section{Implementation}

Our goal was to export the content of the UW course to the community colleges. The UW materials included archived lectures, homework, and exams. The grading for the courses was centralized, so that UW teaching assistants graded homework and exams. The community colleges granted credits for the courses and formally assigned the grades.

The UW lecture materials were made available in a Windows Media Player format showing the Powerpoint lecture transparencies and a small video image of the instructor. A single camera was used for filming the live lecture. We limited the impact of the filming on the instructor so that it did not compromise his teaching style. For example instructors would write on transparencies and use multiple projectors even though only a single transparency was recorded for the archived version. The writing on transparencies was not recorded. Instructors were requested to repeat student questions so that they would be audible in the archived version.

The community college instructors would show the lec- ture in class after down loading it to a PC. The instructors would stop the lecture as necessary for questions and discussions. Instructors adopted significantly different styles in presenting the material and interacting with students.

The first offering of the TVI course was Autumn 1998, where CSE 143 was shown at a single community college. In Winter 1999, CSE 142 was shown at two community colleges. We also ran several of the on-campus course sections as TVI courses. There was then a break in the project until Winter 2000, where it was resumed on a larger scale to determine how broadly it could be used. Winter 2000 had four sections of CSE 142 taught at community colleges, and Spring 2000 had four 142 sections, and four 143 sections. The initial enrollments in classes ranged from 4 to 30, although some sections had high attrition. Approximately 180 students finished the TVI courses.

We learned many lessons as project progressed and are reporting on a number of them here. Adjustments were made throughout the project, in order to do the best job we could in teaching the students (as opposed to running the cleanest experiments on TVI).

\section{Results}

We are neither claiming that the project was a success nor was a failure. Many lessons were learned. Some of the sections were successful (measured by student grades and evaluations) and others were not. The bottom line is that we are going to continue the project of exporting our introductory courses, but will make some significant modifications to our approach.

We will discuss our main conclusions, and attempt to break them into separate categories, but naturally the issues are interrelated and span any categories that we could create.

\subsection{Evaluation techniques}

There is a lot of data available to use in the evaluation of the project. In terms of numerical data, we gave the students pre and post course questionnaires. We also took surveys of the UW classes to have a basis for comparison. Grade data on students and assignments was also available. Since most of the grading was done at UW, the grading was reasonably consistent. In addition to numerical data, we visited and observed the TVI sections, and also conducted interviews with students and instructors. Email from students, both direct exchanges with students, and anonymous feedback was another source of information.

The full version of the paper will report some numerical results. There were high variations between sections. 
Some sections had a grade distribution similar to UW (including students in 3.8-4.0 range) and positive student evaluations. Other sections had lower grades than UW courses and also negative evaluations. The analysis of data is complicated because of a tremendous number of variables. There were significant differences in students and instructors across sections. We also made significant adjustments to the courses as they were in progress, further complicating the analysis.

\subsection{Administrative model}

The course was run using a centralized grading model. The assignments were from the UW course, and they were graded at UW by TAs. Electronic turnin was used for the homework assignments, and mail delivery for the exams. Logistical difficulties have caused us to drop the centralized grading approach from future use. We believe that there are also strong pedagogical reasons not to centralize the grading.

There were several reasons why we initially adopted a centralized grading model. We wanted to make the program work for locations where staff support was not available for grading, and also to see if we could realize economies of scale in administering the course. We hoped that relying on technology to support electronic turn in and possibly on-line exams we could further automate the course and maybe even achieve a paper-less course. For evaluating the program, the uniformity of grading was a plus for the centralized model. TVI theory also pushed us towards this model - since it was desirable not to have the facilitator the grading authority for the class. (It turned out that the instructors had already established an authority role for the class, so this was not a reason to support centralized grading.)

The logistical problems, in retrospect, were not surprising. For example there were significant delays in grading, and standard grading problems (such as misgraded problems or errors on the answer keys) were magnified by distance. Recruiting TAs was also a problem for us. There were other problems which complicated grading such as accommodating a wide range of schedules. Tracking assignments and exams, and running the electronic turnin of materials was a substantial amount of work.

A critical weakness of the centralized grading was student reaction. The delays and impersonal nature of grading had a negative impact on students. The centralized model also caused to a negative dynamic between the community college students and the UW. Since instructors were not grading their students, they had less of a feel for how the students were performing in classes.

Some adjustments to the grading model were made in the Spring 2000 offering of the course. One instructor (responsible for two sections) took over grading assignment/exams midway through the course. Other instructors graded their own finals. Instructors were initially enthusiastic with offloading the grading (not a big surprise!), but quickly recognized the negatives.

The Stanford TVI program also used centralized administration. One significant difference between our program and Stanford's was that Stanford was granting the course credit, while we were not granting credit (the students received community college credit for the course).

Another approach to grading that we attempted (and abandoned) was having different sections cross grade their material. The logistics and problems with load balancing led us to conclude this was not a viable approach.

\subsection{Delivery}

The live UW lectures were videotaped and then digitally archived. A single camera was used to film the instructor. The archived lectures are viewed with Microsoft Media Player. The majority of the screen is used for the power point slides with a small window for video of the instructor ${ }^{2}$.

We aimed to have limited impact on the instructor so that he could give the lecture as he normally would and have his normal interaction with the class. The instructors would use pens to highlight information on transparencies, and would also use multiple projectors. This information was not recorded in the archived version. Instructors did make an effort to have student questions recorded on the audio tape, but it was not always possible to record the full student comments.

An attempt was made to augment the lecture materials with notes and discussion question to mitigate the effects of the lost material. The notes also identified some sections of the lecture that could be skipped. The materials were of some help, but not all instructors took advantage of them.

\subsection{Class structure}

The UW class consisted of three lecture hours per week plus one or two hours of TA led quiz section. The CC courses met five hours per week, with either two, three or five meetings a week. Our belief was that three meetings per week would be best, and the response from students and instructors suggested that this was correct. However, scheduling constraints caused many of the classes to be scheduled with two or five meetings.

\footnotetext{
${ }^{2}$ The Spring 2000 lectures may be down loaded from www.cs.washington.edu/education/courses/cse142TVI/00sp/slides/TVI.html
} 
Our expectation was that three hours of lecture would take about four and a half hours to cover in the TVI mode. Instructors reported feeling time pressure, and the suggestion was made that discussion was inhibited by concern of getting through lectures on time. Two things we did to reduce lecture time (without removing important content) was to delete UW specific and to indicate portions of the lecture that could be skipped over.

The negatives of too many or too few meetings per week are not surprising and were borne out by experience. With five meetings per week, there was not enough time in a class session to view a single lecture so significant time was used in reestablishing context. With only two meetings per week, the individual sessions were too long to maintain an interactive atmosphere. The five day gap between classes caused difficulties for some students.

An issue for students was the concern that the UW students were getting something extra in quiz section. Our model for the course was that the discussion while viewing the lecture would have the same purpose as the quiz section. To alleviate the student concerns, we made UW quiz section materials available to the instructors.

\subsection{Student reaction}

Student reaction was mixed - some students were positive about the experience, but others were strongly negative.

Students were very sensitive to mechanical issues with the course. The most frequent comment from students was a complaint about instructors writing on the transparencies which could not be seen in the archived lectures. (The writing was probably of little real value, but it was perceived by students as being significant.) Students also expressed frustration about some student questions not being clear on the audio. The projection quality at a number of sites was not very good, so that the smaller fonts on transparencies were not readable. (Students had copies of the transparencies, so this was not a crippling problem). These problems will be addressed for the future.

There were mechanical issues related to HW and exams. Electronic turnin of assignments had a few glitches (primarily related to communication). A surprising positive comment from some students was that they liked the fixed turnin time deadline imposed by an automatic system. Other problems (which were certainly not restricted to a TVI class) were errors in HW assignments and exams. The cost of fixing these errors was high. Tying the TVI course to a live offering of the class put pressure on the production of assignments. Use of archived materials allowed for some error correction - but then there were obvious problems with re-use of materials.
There were also problems in propagating errors (missing some corrections which had been made after materials were originally released).

Students (and faculty) are often negative on distance learning when it means that a live instructor was not giving the lectures. Some students did not know in advance that the course was going to be offered by a TVI format, and some students resented not having the lectures given by the instructor. Some of the instructors could have taught the courses (and had taught them in the past), while other instructors had less familiarity with the material.

Some of the reactions of students to the class were related to the subject as a whole. This is especially true for students taking the course as a requirement who did not feel the material in itself was important for them. It is plausible that students in this group felt more negative about the course.

An important aspect of the project that needs to be considered is the relationship between the university and the community colleges. A driving force for the project was to make university courses available at community colleges to support uniformity across the state, as well as to make it easier for students to move between community college's and four year programs. Students had concerns about the relationship between the University course and the community colleges. The general concern was of outside control of the class, and that it would take away an advantage of community college classes (small class size). Students expressed several specific concerns: one was that they would face more rigorous grading standards and some felt that the UW course as a weedout course for the CS major. They were also worried that they were missing aspects of the UW course. The experiences of the TVI and in class students were different in some respects (although the goal was to make them equivalent). Maybe the most significant difference was that TVI students had less access to assistance on homework from consultants.

Another concern of students was the remoteness caused by the portions of the class which were administered externally. Grading delays, impersonal grading, and lack of opportunity for appeal or clarification were frequent complaints. Another problem was that some of the materials were designed for on campus use and some instructions didn't make sense to the students (e.g., direct references to UW facilities). The more significant problem with this was the appearance that the course was not directed at the TVI students.

\subsection{Tutored Video Instruction}

The major theoretical question for this study was how well did Tutored Video Instruction work, as opposed 
to just how successful were we in exporting a version of our course. Understanding effective ways to offer distance courses is very important, since many believe that distance learning will be pervasive, and technology is making delivery and communication much easier.

In running this program, we wanted to establish that TVI was successful since it offers an excellent combination of live interaction and archived materials. It could allow the offering of courses with a broader range of instructors. There were too many variable in our project for us to draw a definite conclusion. A direct experiment would require a stable offering of the course, perhaps doing comparisons between sections using TVI and other methods of instruction.

We conducted observations of some classes and kept track of the degree of interaction between students. There were some occasions where the "best case interactions" occurred, with discussion between students to clarify a point. However, most of the interactions were between instructor and student, often initiated by the instructor. The instructors had very different styles in running TVI sections. They made different use of material (some ran lectures straight through - others jumped around) and they had different levels of directing students. Instructors began their courses talking about the TVI concept to the students, and we had a pre-course meeting with the instructors to talk about running a TVI course. There is opportunity for a more formal introduction to running a TVI course.

The comments of the students did not address the TVI aspects of the course. The interaction with the tutor was not the dominant concern of the students. Student comments more often related to course mechanics and the quality of the materials.

A question that can be raised is how suitable is the course material for discussion. Students generally did not appreciate the more abstract material such structuring programs and style, but preferred the more language mechanistic aspects. Language details might not be the best material for discussion without degenerating into trivia.

There was a broad range of community college instructors involved with the course. Some were CS instructors who had taught the course and other were nonCS instructors without background in the subject. In the TVI model of Gibbons the instructor is referred to as a "para-professional tutor" who has the background equivalent to someone who has successfully completed the course. It was observed that the types of questions that students need to have resolved were often fairly challenging - such as questions of language details (which can be tricky in $\mathrm{C} / \mathrm{C}++$ ), as well as needing help on the homework. A recognized weakness of our offerings was that the instructors were often not familiar with the homework.

\section{Revised approach}

How do we change the method for exporting our course in reaction to these experiences? Our goal is to export our courses to give students across the state access to a high quality course in introductory programming. We would like to do this in an manner that is efficient in costs and effort, and is also financially sustainable. We are also trying to simultaneously get the advantages of using archived materials and having students work in a group with an instructor.

\subsection{Revised approach}

There are two major changes that we are going to implement for future offerings of the course. First of all, we are going to retreat from the centralized administration of the course. The amount of effort in centralizing the grading outways the benefits of uniformity. The centralized grading also appeared to have a negative impact on the students perception of the course. This will change the role of the local instructor, and will hopefully make the course more closely identified with the local institution. It will lead to some increase in the workload of the local instructor and may make it more difficult to find suitable instructors.

The other major change will be to produce new materials with higher production values. We plan to use studio produced versions of the lectures which are aimed at the TVI audience. The students were distracted by the quality of live lectures (even if most of the content was preserved). A benefit of studio production will be that the total lecture time will be significantly reduced, leaving more class time for discussion and other activity. We estimate that the studio lectures will take about 20 hours to cover what is covered in 30 hours of live lectures. We will have savings in time by not having to reestablish context between lectures, not having interruptions for questions, and not addressing administrative matters.

The new model for running the TVI course will be based on distributing the course materials as opposed to running the entire class. In addition to lectures, homework assignments, exams, and course notes will be made available.

\section{References}

[1] Gibbons, J. F., Kincheloe, W. R., and Down, K. S. Tutored videotape instruction: A new use of electronics media in education. Science 195, 3 (1977), 1139-1146. 